\title{
Microstructure Modelling of Dual-Phase Steel Using SEM Micrographs and Voronoi Polycrystal Models
}

\author{
S. Katani - S. Ziaei-Rad • N. Nouri • \\ N. Saeidi · J. Kadkhodapour • \\ N. Torabian $\cdot$ S. Schmauder
}

Received: 20 February 2013/Revised: 30 April 2013/Accepted: 3 May 2013/Published online: 22 May 2013

(C) Springer Science+Business Media New York and ASM International 2013

\begin{abstract}
The microstructure of dual-phase (DP) steels is composed of a matrix of ferrite reinforced by islands of martensite and the common interphase boundaries. To study the mechanical behavior of DP steels, steel with $45 \%$ ferrite and 55\% martensite was fabricated and tested in the laboratory. Two types of finite element models were then created based on SEM images. The first model directly created the grains and boundaries from the SEM images, while the second model used a Voronoi type algorithm to construct geometries which are statistically similar to the SEM images. The models consider the measured morphology of ferrite, martensite, and their phase boundaries. The Gurson damage model was then used for the ferrite and boundary regions. The obtained results correctly predicted the failure mechanisms in a DP material. The results indicate that the deformation is localized due to microstructural inhomogeneities and the nucleation of voids in the boundaries between the ferrite and martensite grains. The good correlation between
\end{abstract}

S. Katani $\cdot$ S. Ziaei-Rad $\cdot$ N. Nouri $\cdot$ N. Torabian $(\square)$

Department of Mechanical Engineering, Isfahan University

of Technology, 84156-83111 Isfahan, Iran

e-mail: n.torabian@me.iut.ac.ir

N. Saeidi

Department of Material Engineering, Isfahan University of Technology, 84156-83111 Isfahan, Iran

J. Kadkhodapour

Department of Mechanical Engineering, Shahid Rajaei

University, Tehran, Iran

S. Schmauder

Institut für Materialprüfung, Werkstoffkunde und

Festigkeitslehre (IMWF), University of Stuttgart, Stuttgart, Germany the numerical and experimental observations from SEM micrographs shows the efficiency of the proposed models in predicting the failure mechanism of DP steels.

Keywords Dual-phase steels · Finite element method · Gurson damage model $\cdot$ Microstructure

\section{Introduction}

Nowadays, in material engineering, the use of lightweight components is a fundamental requirement. For developing material properties, and also due to the economic and ecological considerations, the weight of a structure should be reduced and at the same time its structural quality should be strengthened. Multiphase steels such as dualphase (DP) steels, which exhibit an excellent combination of strength and ductility, have been widely used in the automotive industry for the purpose of weight reduction and saving energy. The high strength of multiphase steels is the consequence of grain refinement and precipitation hardening induced by the coexistence of softer and harder phases and various grain sizes. The fraction and spatial distribution of the different phases controls their practical effects, which play a key role in the complex behavior of these steels $[1,2]$.

The DP steel used in this study is AISI 5115, which offers impressive mechanical properties such as continuous yielding behavior, high work hardening rate, and superior strength-ductility combination, and is used for machine elements such as cam shafts, gears, and other transmission elements after surface treatment by carburizing or nitriding. Generally, these steels consist of a soft phase, i.e., ferrite and a relatively hard martensite phase. 
The mechanical properties of these steels are primarily related to the volume fraction of each phase. Ferrite in the microstructure improves the toughness and elongation, but martensite improves the strength and hardness. The existence of both high strength and good toughness simultaneously is one of the most important characteristics of DP steels. On the whole, the formation of a second hard phase in the ductile matrix usually sacrifices ductility.

Generally, there exist two methods for producing DP steels, thermo-mechanical treatment and intercritical annealing. In the first case, Coldren and Tither [3] showed that a DP structure is developed during cooling after hot rolling. In the second method, the DP structure is formed after intercritical annealing of a previously rolled product [4-6]. Intercritical annealing leads to the formation of islands of austenite that transform to martensite or some other low-temperature transformation products, such as bainite, during rapid cooling.

Generally, various investigations have been conducted on simulation of tensile behavior and failure mechanisms of multiphase steels [7-11]. Uthaisangsuk et al. presented a model to describe the influence of the multiphase microstructure on the complex failure mechanism. In this investigation, two failure modes were observed at a microscale level: cleavage and dimple fracture. Simulations were also carried out for DP steels by using the Gurson-Tvergaard-Needleman (GTN) model with a two void nucleation mechanism [1]. Ohata et al. developed a two-phase polycrystalline FE model together with a damage model for the simulation of microvoid formation and subsequent interaction followed by ductile cracking. In their simulation, the grain boundaries were omitted and the focus was mainly on the different phases [12].

In this article, first a DP steel was fabricated by a heat treatment procedure reported in literature. Some experiments were then carried out on the produced steel to determine its microstructural characteristics. Two sets of finite element models were then created. The geometry of the first set was constructed from the SEM images of the material, while the grain distribution of the second set was created by a novel random algorithm.

In spite of the extensive work on modelling the failure behavior of multiphase steels, there are limited investigations which have taken the grain boundaries effects into consideration [13-15]. Wei and Anand [13] employed an elastic-plastic grain boundary interface model which accounted for irreversible inelastic sliding-separation deformations at the grain boundaries prior to failure. Wei et al. [14] used a rate-dependent amorphous plasticity model which accounted for cavitations and related failure phenomena to model the grain boundaries. However, in this study, the effects of grain boundaries on the failure behavior of a DP steel are considered by employing damage mechanics; different models were constructed and analyzed to simulate the behavior of the material during tensile tests. The GTN damage model was employed to simulate the ductile cracking behavior of the material. Finally, the numerical results were compared with experimental observations and the failure mechanisms were explained in detail.

\section{Material Fabrication and Testing}

The steel used in this investigation was AISI 5115 with the chemical composition presented in Table 1.

The material was received as cold rolled bars with a diameter of $30 \mathrm{~mm}$. Longitudinal tensile specimens were machined according to ASTM A370. After austenitizing at $900{ }^{\circ} \mathrm{C}$ for $15 \mathrm{~min}$, the specimens were soaked in $730{ }^{\circ} \mathrm{C}$ for $200 \mathrm{~min}$ and then quenched into cooled water.

Three round tensile specimens were fabricated from the produced steel and the tensile tests were performed at a cross-head speed of $2 \mathrm{~mm} / \mathrm{min}$ at room temperature. The obtained stress versus strain diagrams are depicted in Fig. 1. From this figure, it is clear that the test results for the three samples coincide with each other with a maximum difference of 5\%, indicating that the results are repeatable and also that the steel is produced homogenously. The material behavior consists of two distinct regions. In the first region, which is up to $0.4 \%$ of strain, the material behaves linearly. Moreover, the hardening characteristic of the produced DP steel can be properly approximated by a linear hardening rule. The mechanical properties of the material are summarized in Table 2.

The microstructure was characterized using both optical metallography and scanning electron microscopy. An optical micrograph of the material is presented in Fig. 2 which shows that the material microstructure consists of martensite islands distributed in a ferritic matrix. Metallographic studies were carried out on samples prepared by polishing and etching with Nital $2 \%$. Then, the volume fraction of each phase was measured using an image analyzer on metallographic sections. The ferrite and martensite volume fractions were 45 and 55\%, respectively.

The microstructure was also analyzed by SEM and EDS. SEM micrographs taken from different regions of the produced steel are shown in Fig. 3. Moreover, grain boundaries were studied by EDS and map analysis. As shown in Fig. 4, different parts were analyzed but there

Table 1 Chemical composition of AISI 5115 steel

\begin{tabular}{lllllll}
\hline Alloying element & $\mathrm{C}$ & $\mathrm{Si}$ & $\mathrm{Mn}$ & $\mathrm{Cr}$ & $\mathrm{S}$ & $\mathrm{P}$ \\
\hline$\%$ Weight & 0.25 & 0.4 & 1.1 & 1.0 & 0.025 & 0.035 \\
\hline
\end{tabular}


Fig. 1 Measured stress-strain curve obtained from three different samples

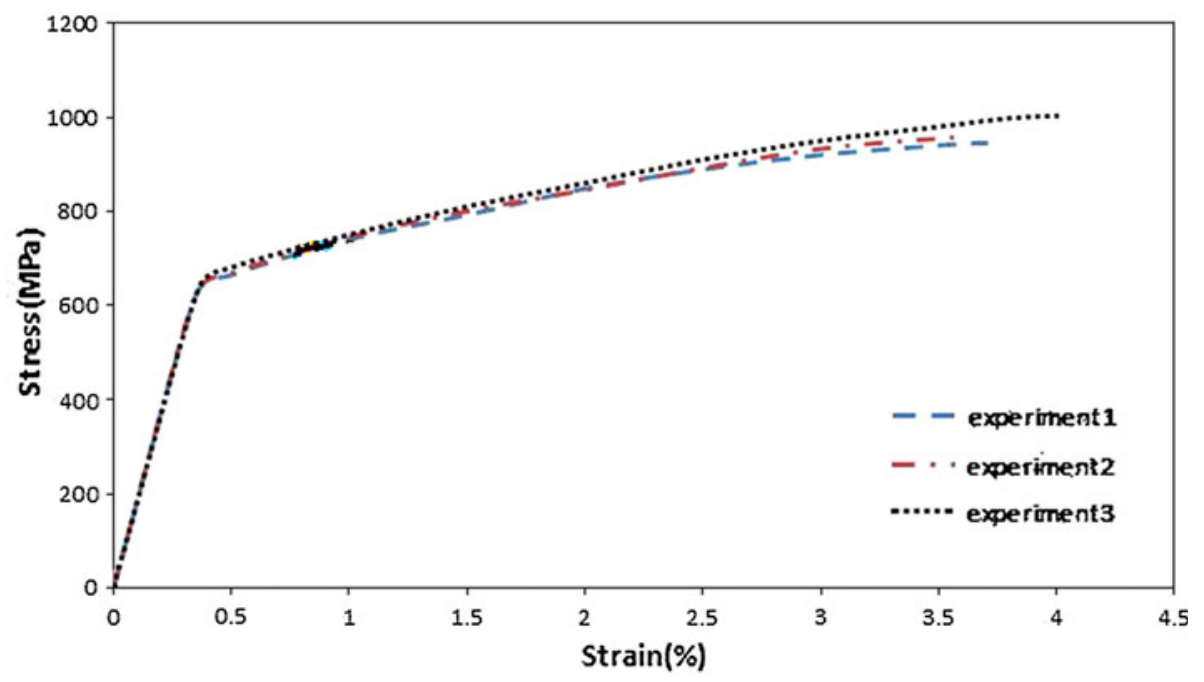

Table 2 Mechanical properties of the dual-phase steel

\begin{tabular}{ll}
\hline Young's modulus, $E(\mathrm{GPa})$ & 193 \\
Yield stress, $\sigma_{\mathrm{y}}(\mathrm{MPa})$ & 640 \\
Ultimate stress, $\sigma_{\mathrm{u}}(\mathrm{MPa})$ & $950-1,000$ \\
Fracture strain, $\varepsilon_{\mathrm{u}}(\%)$ & $3.5-4$
\end{tabular}

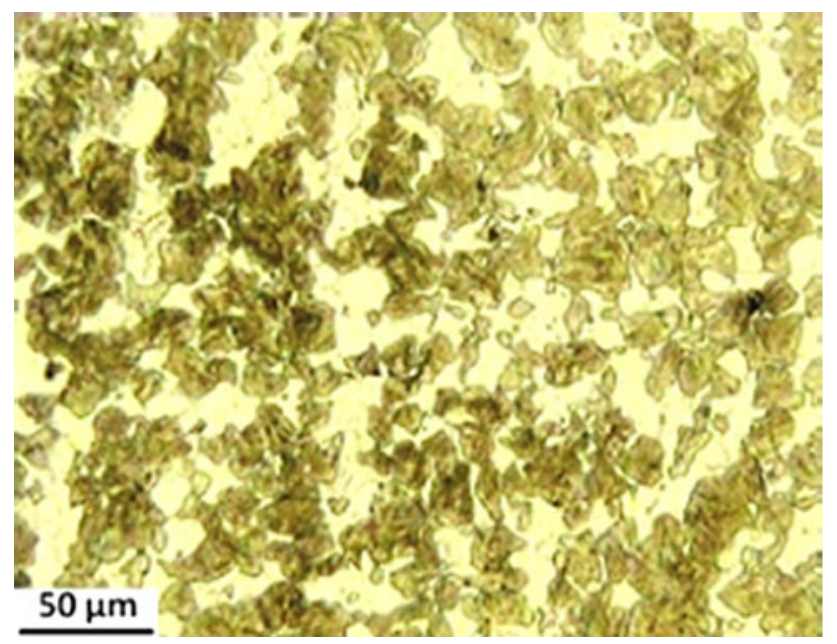

Fig. 2 Optical micrograph of produced dual-phase AISI 5115 steel (bright phase ferrite, dark phase martensite)

was no preferred segregation of elements in the grain boundaries observed, and also no carbide or any other particles were detected in the grain boundaries. So it can be concluded that the microstructure is homogenous and there is no difference between the grain boundary and matrix from the view point of alloying elements. In other words, no partition of $\mathrm{Mn}, \mathrm{Si}$, or $\mathrm{Cr}$ exists between the two phases. This was probably due to insufficient time for partitioning of the substitutional solutes to occur during austenite decomposition.

\section{Geometry of Microstructure}

Microstructure Geometry from SEM Images

After production of the steel, some processes were used to prepare it for photographing in microdimensions. Next, pictures were taken from some regions of the manufactured steel using scanning electron microscope. It should be mentioned that each picture approximately includes 150 grains. The grain size was $14-20 \mu \mathrm{m}$.

The SEM images of different regions of the material (Fig. 3) were loaded into the MATLAB environment. The first step is to recognize the phases. The identification of phases is performed by the use of MATLAB image processing software with a novel idea that uses the RGB index range of the colors in the image to recognize ferrite and martensite phases.

As the boundaries play a significant role in the material behavior, it is important to recognize boundaries from the phases. This is carried out by considering the range of colors corresponding to the boundaries in the RGB index. The developed method is able to separate grain boundaries from phases (ferrite and martensite). In the proposed procedure, the greater the number of pixels is, the more precisely the phases can be identified.

At the end of this stage, the pictures are mapped into a matrix involving arrays which show the types of the phase and boundary. The material which has been assigned to the element of the $i$ th row and $j$ th column of the matrix corresponds to the color of the pixel in the image.

In the next stage, a code is written which creates an array of rectangles with their corresponding material. Finally, a model similar to the real image is constructed (Fig. 5).

In the above-mentioned methodology, the quality of the image is proportional to the computational cost. Although by increasing the picture size the accuracy of 

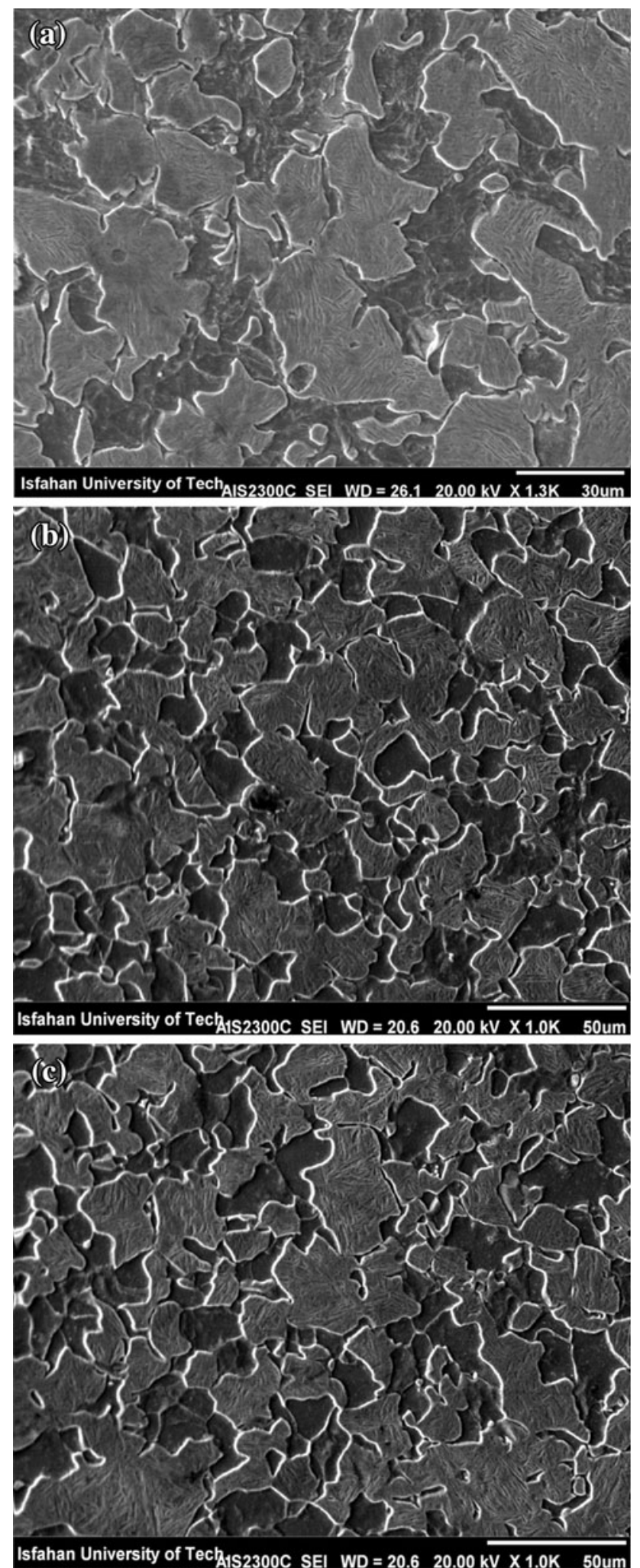

Fig. 3 SEM micrographs of produced dual-phase AISI 5115 steel (SEM images from different regions are later used for finite element modelling of microstructures). (a) Region 1. (b) Region 2. (c) Region 3

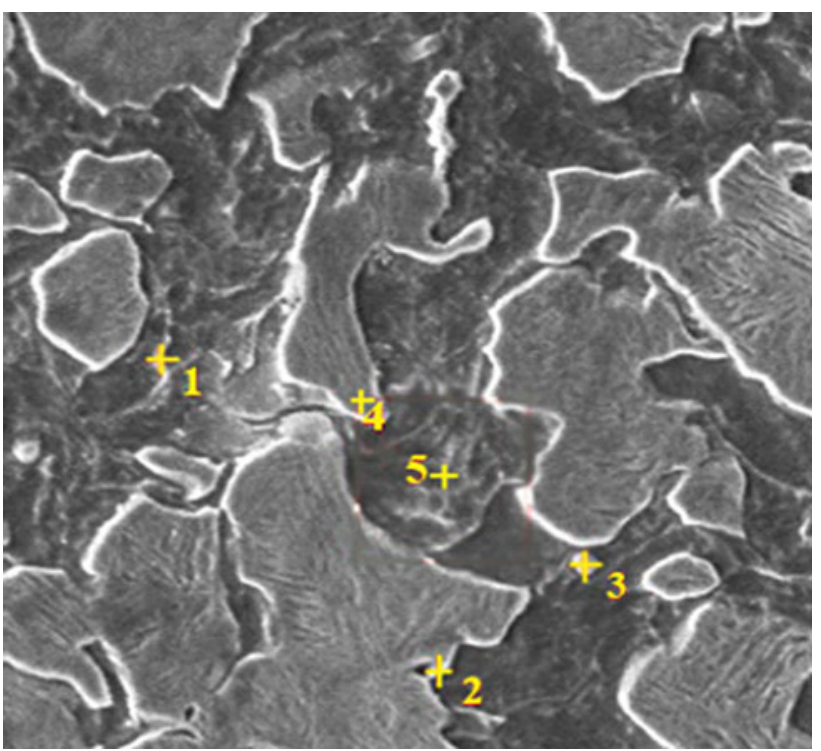

Fig. 4 EDS analysis at different points of the microstructure $(1,5$ ferrite grains; 3, 4 martensite; 2 boundary)

the model in predicting the material properties increases, the model size (number of rectangles) is limited to the hardware available.

To reduce the required computational time, the program defines every congeneric 256 pixels as a block. In this way, the time of solving the problems by the finite element method decreases considerably. Therefore, it is possible to use high accuracy images to solve the problems. In the next stage, a finite element code is used to compare the numerical results with the experimental data. The image processing algorithm can be summarized as follows:

1. Reading the SEM image

2. Recognizing the range of the colors

3. Identifying the phases and separating of grain boundaries from phases

4. Assigning material to the colors of the pixels

5. Mapping of the material matrices to the FE model

Figure 6 depicts the results of different stages from the SEM image to the final FE model.

A similar procedure was also applied to the images of Fig. 3(a, c); however, the results are not reported here for the sake of brevity.

It should be mentioned that in the FE models the mesh size is the same as the size of the pixels. In the picture, the number of pixels in the $x$ and $y$ directions are 330 and 265, respectively. However, it is possible to use a finer mesh.

Linear-2D plane strain elements were used throughout the simulations. As mentioned previously, the number of elements has a significant effect on the accuracy of the 
Fig. 5 The image processing procedure used for recognition of phases and boundaries from SEM images

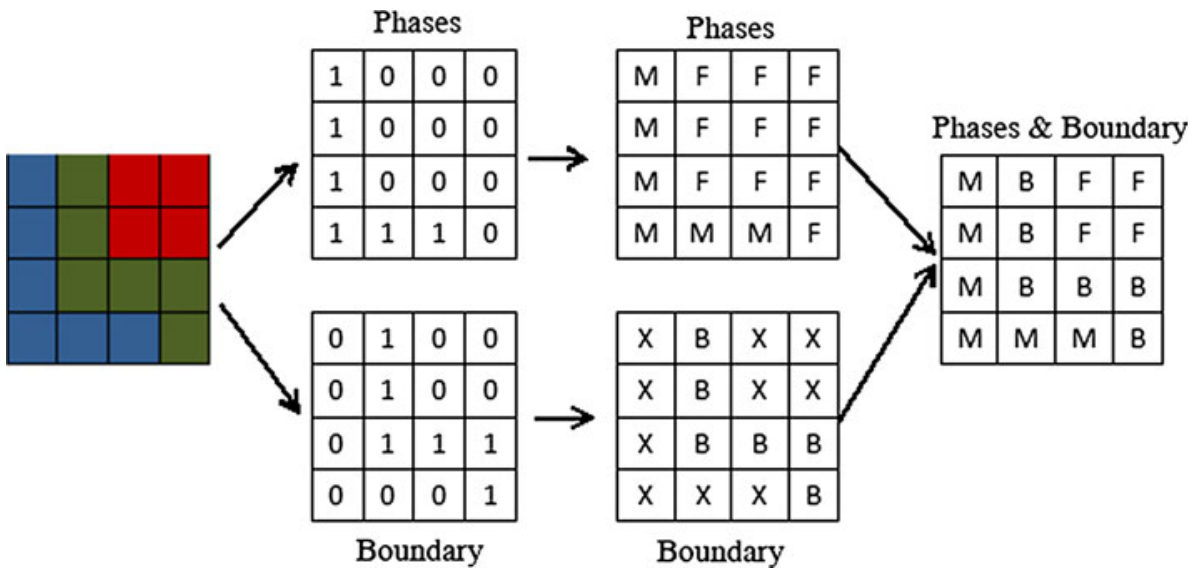

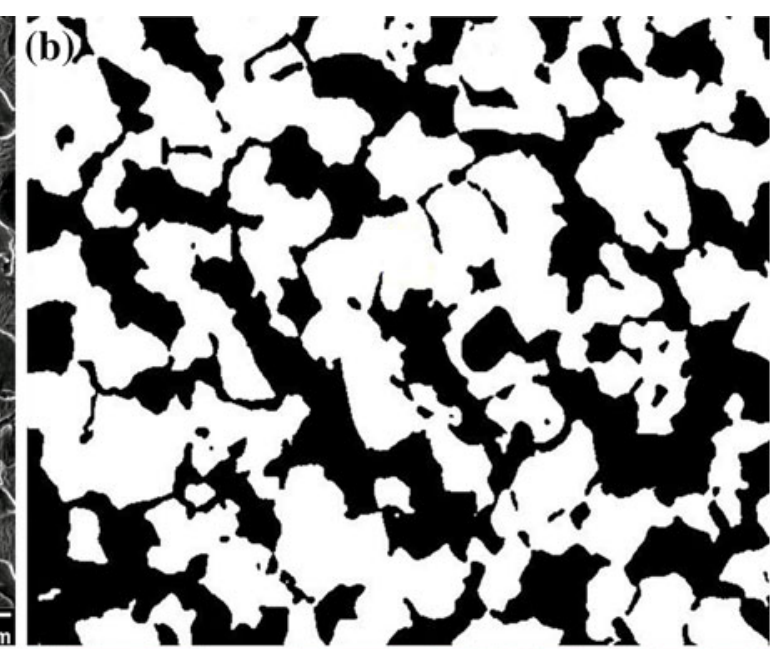
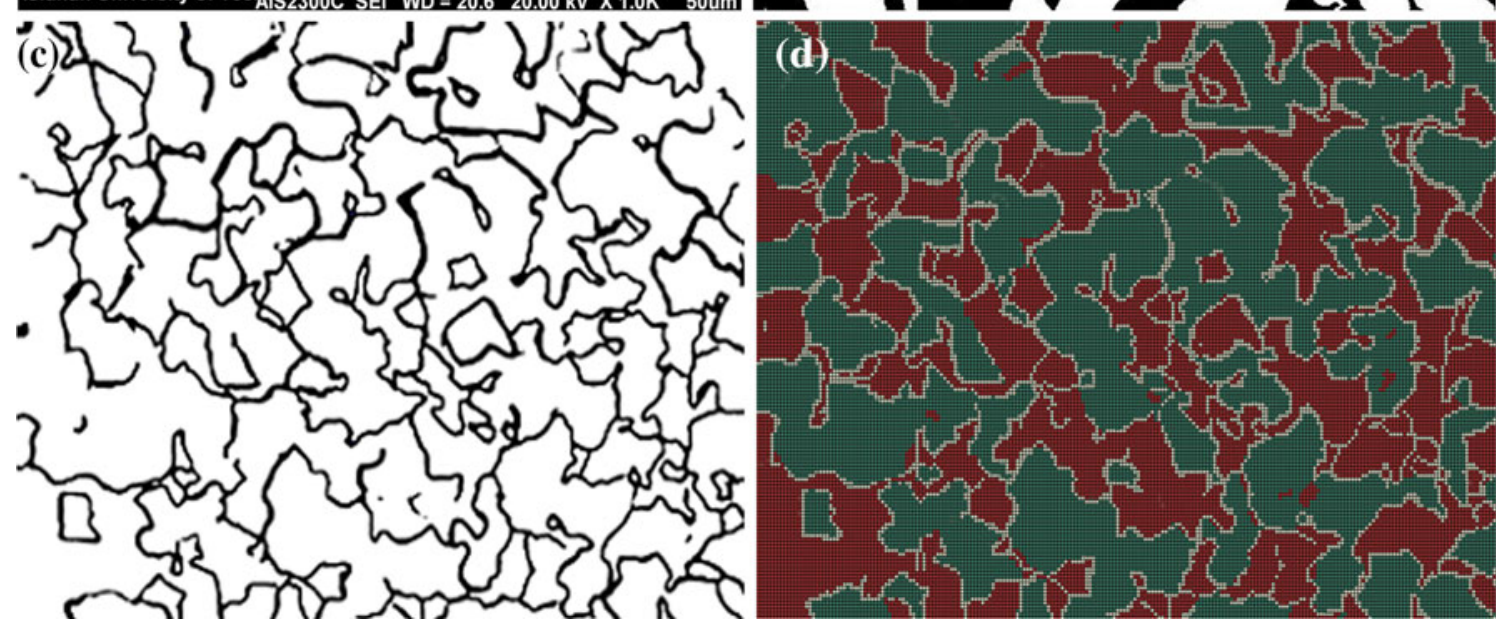

Fig. 6 Image processing procedure for the image of Fig. 3b. (a) SEM image. (b) Recognition of phases (white color martensite, black color ferrite). (c) Separation of boundary from phases. (d) FE model

results. A mesh density study was also carried out with images of various pixel numbers, and the results indicated that using images with $330 \times 265$ pixels, the accuracy of the results would be acceptable.
Random Geometry

Initially, the averaged grain dimensions and volume fraction of each phase was calculated using SEM micrographs. Grain 
size and distribution of each phase was calculated from SEM images of various regions of the investigated material. Having three images on the microscale, the grain size in both the horizontal and the vertical directions can be computed. The obtained grain size of the ferrite or martensite phases is then used to construct an accurate random model.

Figure 7 shows the distribution of ferritic grain existing in three SEM images versus the grain size in two directions, i.e., vertical and horizontal. Using statistical analyses, the maximum grain size of ferrite was estimated to be around $15 \mu \mathrm{m}$, with a tolerance of $2 \mu \mathrm{m}$ in both the horizontal and the vertical orientations.

Figure 8 presents the statistical data for the martensite phase. The results show a dimension of $14 \mu \mathrm{m}$ with a tolerance of $1 \mu \mathrm{m}$ in either direction.

In this study, a code is developed to generate 2D Voronoi tessellation data just by inputting a set of nodes. The program has the ability to tessellate systems with different shapes and with periodic and non-periodic boundaries.

There are a few algorithms on scattering points in a plane for creating a Voronoi tessellation with partly prescribed cell sizing. To the best of authors knowledge, there is no mathematical methodology for prescribing the type and volume fraction and size distribution of the Voronoi cells. However, a novel procedure is proposed for a broad range of grain sizes and fractions without limitations in the number of the grain size set.

The idea is to extract the input points which are used in the Voronoi tessellation from a packing problem (granular simulation). This is done using algorithms that exist in a discrete element method (DEM). Details of the algorithm and the modelling scheme can be found in the previous article of authors [16]. The Voronoi tessellation created from the data of DEM is presented in "Comparison between results obtained from random geometry generation and experimental data" section.

\section{Material Modelling}

\section{Mechanical Properties}

The mechanical properties of the investigated steel were identified through tensile tests, as discussed in "Material fabrication and testing" section. In DP steels, the combination of chemical composition and processing conditions results in the production of an extensive range of microstructures leading to various mechanical behaviors. Different studies have been presented to accurately measure the mechanical properties of each phase [17, 18]. In this study, the empirical relation proposed by Rodriguez and Gutierrez was employed to estimate the stress-strain relation for each single phase [19]:

$\sigma=\sigma_{0}+\Delta \sigma+\alpha \cdot M \cdot \mu \cdot \sqrt{b} \cdot \sqrt{\frac{1-\exp \left(-M \cdot k \cdot \varepsilon^{\mathrm{p}}\right)}{k \cdot L}}$

where the term $\sigma_{0}$ describes the effect of the Peierls stress and of the elements in the solid solution, defined as

$$
\begin{aligned}
\sigma_{0}= & 77+80 \% \mathrm{Mn}+750 \% \mathrm{P}+60 \% \mathrm{Si}+80 \% \mathrm{Cu} \\
& +45 \% \mathrm{Cr}+11 \% \mathrm{Mo}+5,000 \mathrm{~N}_{\mathrm{ss}}
\end{aligned}
$$

where $N_{\text {ss }}$ represents the nitrogen solid solution in mass percent. Moreover, $\alpha$ is a constant, $M$ is the Taylor factor, $\mu$ refers to the shear modulus, $b$ is the magnitude of the Burgers vector, $\varepsilon^{\mathrm{p}}$ is the plastic strain, $L$ denotes the
Fig. 7 Number of grains versus grain size of the ferrite phase

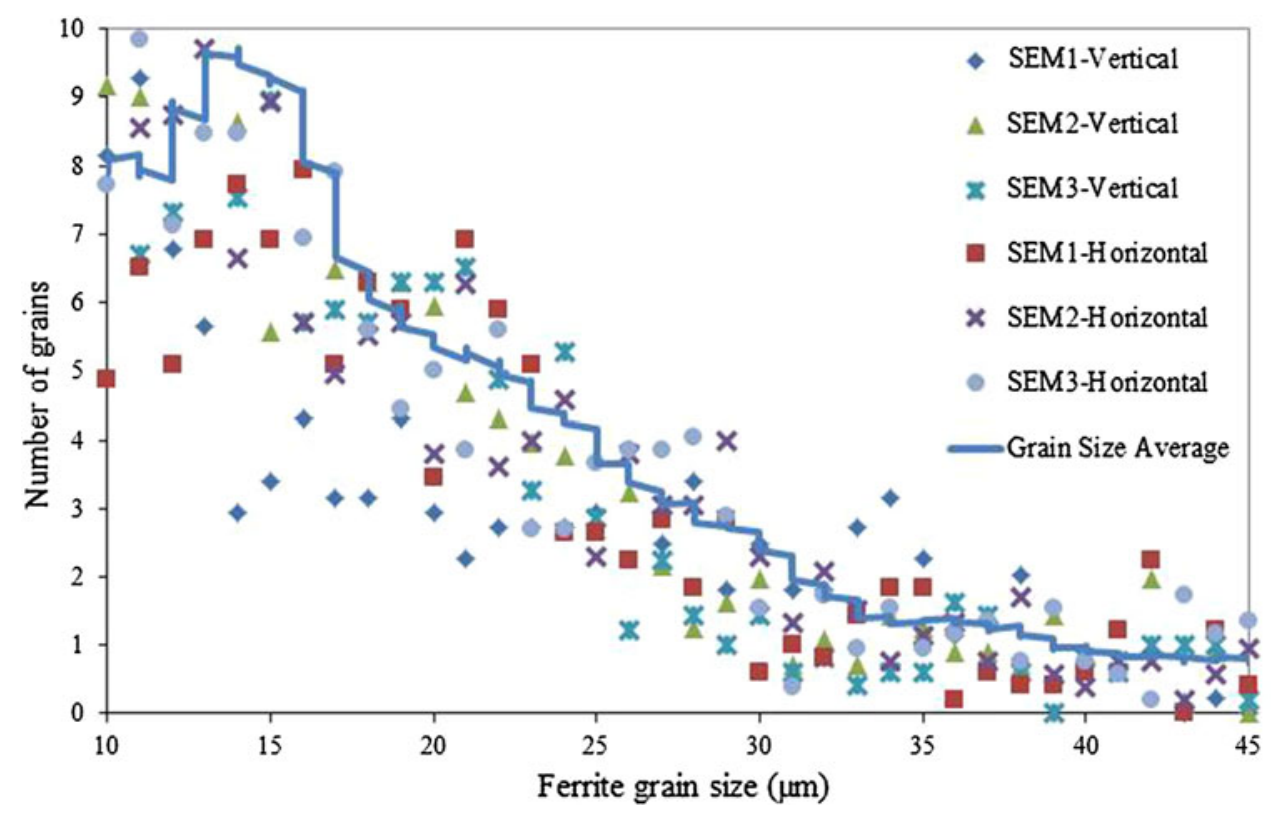


Fig. 8 Number of grains versus grain size of the martensite phase

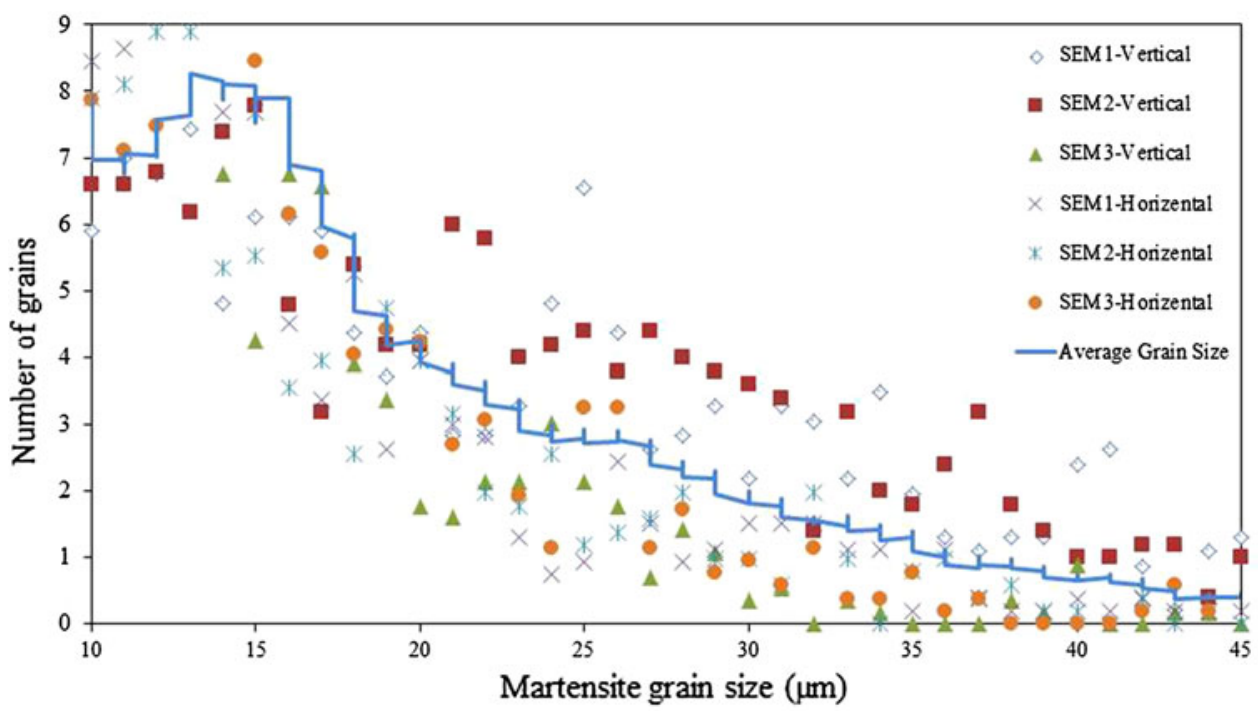

dislocation mean free path, $k$ is the indication of the recovery rate, and $\Delta \sigma$ is the additional strengthening due to the precipitation and carbon in solution. The corresponding values of these parameters were extracted from Ref. [2].

Finally, the calculated stress-strain curves for different phases are shown in Fig. 9. It demonstrates that the carbon content has a significant influence on the strength for both, martensite and ferrite. In numerical modelling, a J2 plasticity model was assigned to both phases using the stressstrain curve depicted in Fig. 9.

Experimental investigations reported in Ref. [20] for DP steels indicate that the hardness at ferrite-martensite and ferrite-ferrite boundaries is higher than in the ferrite phase. Therefore, the hardening and the yield stress of grain boundaries were set to 1.35 times of the ferrite phase. To estimate this value first an average value for the boundary thickness was calculated from Fig. 6(c). Then using the estimated thickness and nanohardness graph for DP steel presented in Ref. [20], an average value for the ratio of the boundary hardness to the ferrite hardness was extracted. Utilizing this value, the calculated stress-strain results are

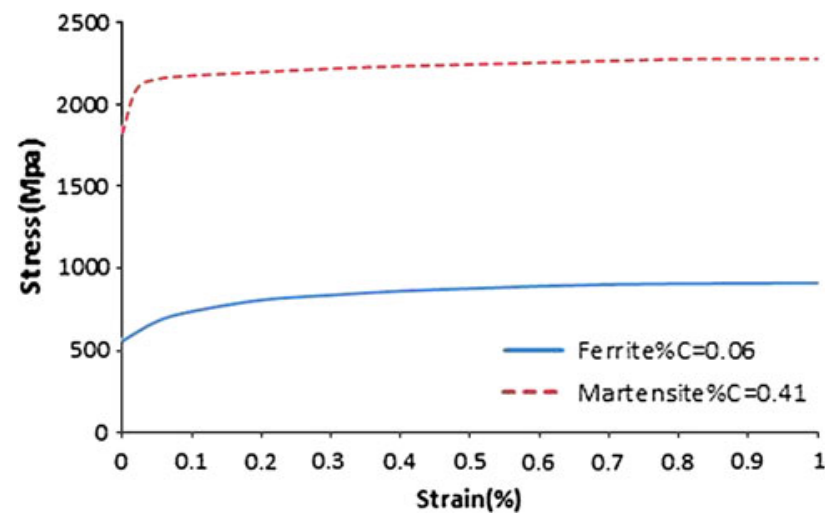

Fig. 9 Stress-strain curves for ferrite and martensite phases in relatively good agreement with experimental data. However, further experimental measurements need to be done on this specific steel to obtain more accurate values of these parameters.

\section{The GTN Damage Model}

The Gurson model is an appropriate model for simulating the damage evolution inside a ductile material. It is well known that ferrite shows ductile behavior during failure, while martensite is a hard phase with a high ultimate stress. Therefore, in this study, the ferrite behavior was simulated by the GTN model and elastoplastic behavior was assigned to the martensite phase. Moreover, according to the deformation behavior of grain boundaries described in Ref. [13], a GTN model was used here for simulating the behavior of boundaries. The material and damage models used for each separate phase are presented in Table 3.

The GTN model is based on an isotropic matrix material and a single spherical void, so that the void existence and growth make a contribution in the formulation of a yield equation. The most widely used form of GTN, which applies to strain-hardening materials under the assumption of isotropic hardening, has the form

$\emptyset=\left(\frac{\sigma_{\mathrm{V}}}{\sigma_{\mathrm{y}}}\right)^{2}+2 q_{1} f^{*} \cosh \left(\frac{3}{2} \frac{q_{2} \sigma_{\mathrm{H}}}{\sigma_{\mathrm{y}}}\right)-\left(1+q_{3} f^{* 2}\right)=0$

Here, $\sigma_{\mathrm{V}}$ and $\sigma_{\mathrm{H}}$ represent the macroscopic equivalent stress and the hydrostatic macroscopic stress, respectively. Also $\sigma_{\mathrm{y}}$ is the yield stress of the matrix material. Furthermore, $q_{1}, q_{2}$, and $q_{3}$ are the most important parameters in GTN model and should be selected in a way to obtain a proper fit between the numerical and experimental results $[1,21]$. 
Table 3 Mechanical models used for each phase

\begin{tabular}{lll}
\hline Materials & Hardening model & Damage model \\
\hline Ferrite & Elastic-plastic & GTN damage \\
Grain boundary & Elastic-plastic & GTN damage \\
Martensite & Elastic-plastic & No damage model \\
\hline
\end{tabular}

The damage in the form of a void volume fraction is described by $f^{*}$, the effective void volume fraction given by

$$
f^{*}(f)=\left\{\begin{array}{ll}
f & \text { if } f<f_{\mathrm{c}} \\
f_{\mathrm{c}}+\frac{1 / q_{1}-f_{\mathrm{c}}}{f_{\mathrm{f}}-f_{\mathrm{c}}}\left(f-f_{\mathrm{c}}\right) & \text { if } f>f_{\mathrm{c}}
\end{array},\right.
$$

where $f$ is the void volume fraction and $f_{\mathrm{c}}$ and $f_{\mathrm{f}}$ are the critical void volume fractions at the onset of coalescence and at total failure, respectively [22].

The total rate of void evolution in this model is decomposed into the growth rate of the existing voids and the nucleation rate of new voids, as follows [1]:

$\dot{f}=\dot{f}_{\text {growth }}+\dot{f}_{\text {nucleation }}$

where

$$
\begin{array}{r}
\dot{f}_{\text {growth }}=(1-f) t r \dot{\varepsilon}^{\mathrm{p}} \\
\dot{f}_{\text {nucleation }}=A \dot{\varepsilon}_{M}^{\mathrm{pl}}
\end{array}
$$

in which $\varepsilon^{\mathrm{pl}}$ is the plastic strain tensor, $\varepsilon_{M}^{\mathrm{pl}}$ denotes the equivalent plastic strain, and $A$ is the nucleation parameter defined as [1]

$A=\frac{f_{\mathrm{n}}}{s_{\mathrm{N}} \sqrt{2 \pi}} \exp \left[-\frac{1}{2}\left(\frac{\varepsilon_{M}^{\mathrm{pl}}-\varepsilon_{\mathrm{N}}}{s_{\mathrm{N}}}\right)^{2}\right]$,

where $f_{\mathrm{n}}$ is the volume fraction of void nucleating particles, $\varepsilon_{\mathrm{N}}$ and $s_{\mathrm{N}}$ are the mean and standard deviation of the nucleating strain distribution, respectively.

In this model, the initial porosity, $f_{0}$, is equal to the volume fraction of inclusions, and thus was set equal to 0.001 , as suggested by Ref. [1]. Moreover, $f_{\mathrm{n}}$ was set to 0.04 according to Ref. [23]. Other damage parameters were obtained through finite element calibration as $\varepsilon_{\mathrm{N}}=0.2$, and $s_{\mathrm{N}}=0.2$. The identification procedure of $q_{1}$ and $q_{2}$ is discussed in the following section.

\section{Identification of the Material $q$-Parameters}

It is well known that for a material obeying the GTN constitutive relation, the stress-strain behavior, which strongly affects the material fracture resistance, is sensitive to $q_{1}$ and $q_{2}$ parameters [24]; therefore, determination of the $q$-parameters is crucial when employing the GTN damage model. In this study, $q_{1}$ and $q_{2}$ are determined through the calibration procedure suggested by Kim et al. [24], as follows:

A representative material volume (RMV) is modelled by two approaches; one, which is called the voided cell method, contains a discrete void of initial volume $f_{0}$ governed by the $J_{2}$ theory of plasticity, and the other is a homogeneous continuum with the same initial volume fraction characterized by the GTN constitutive relation. Both unit cells are subjected to the same loading history.

The parameters $q_{1}$ and $q_{2}$ are calibrated to minimize the difference in the predicted stress-strain curves between the GTN model and the voided cell model. Figure 10 shows the stress-strain curves obtained from the two approaches. In Fig. 10(a), $q_{2}$ is fixed at 1.1 and $q_{1}$ changes from 1.02 to 1.4, while in Fig. 10(b), $q_{1}$ is fixed at 1.08 and $q_{2}$ varies from 0.94 to 1.4. According to Fig. 10(b), for $q_{1}=1.08$ and $q_{2}=0.94$ the results obtained from the GTN model would be in a good agreement with the voided cell model predictions; therefore, the calibrated values for $q_{1}$ and $q_{2}$ are set to 1.08 and 0.94 , respectively. The material damage parameters for the investigated DP steel are summarized in Table 4.
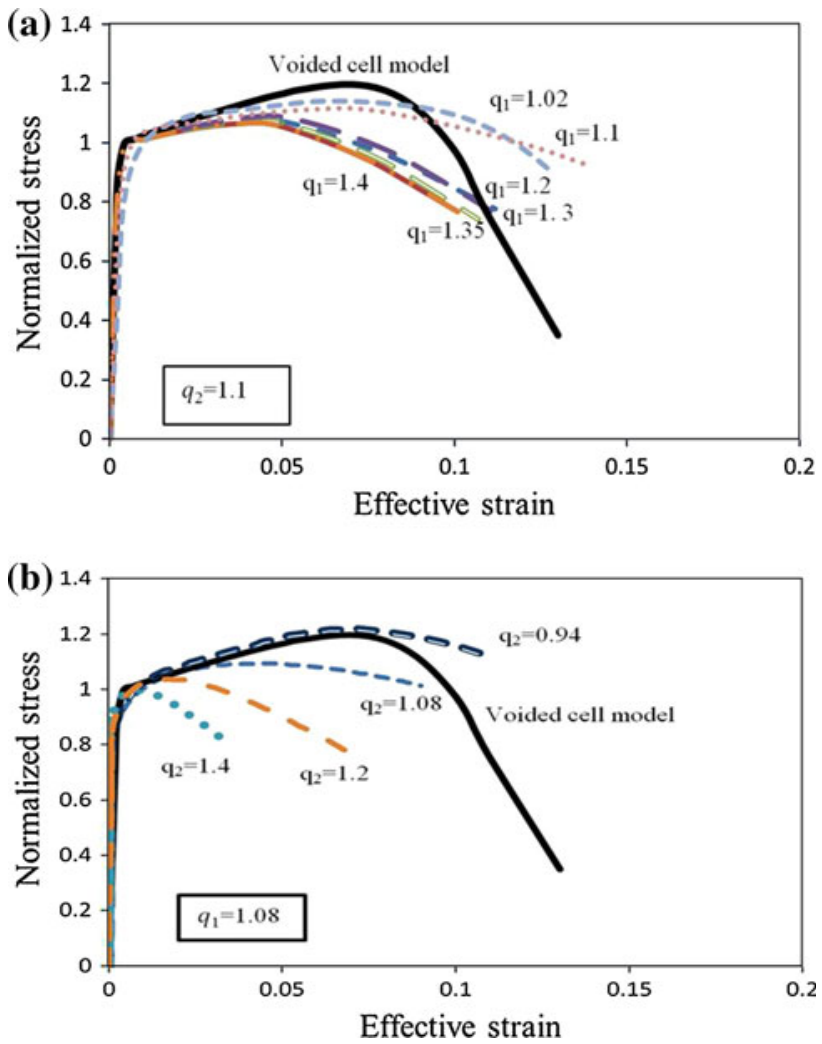

Fig. 10 Macroscopic stress-strain curves for (a) fixed $q_{2}$, (b) fixed $q_{1}$ 
Table 4 Damage parameters for AISI 5115 dual-phase steel

\begin{tabular}{llllllll}
\hline$q_{1}$ & $q_{2}$ & $f_{0}$ & $\varepsilon_{\mathrm{N}}$ & $f_{\mathrm{n}}$ & $s_{\mathrm{N}}$ & $f_{\mathrm{f}}$ & $f_{\mathrm{c}}$ \\
\hline 1.08 & 0.94 & 0.001 & 0.2 & 0.04 & 0.2 & 0.29 & 0.08 \\
\hline
\end{tabular}

\section{Numerical Results}

In the finite element simulations, the following boundary and loading conditions were considered: In image processing-based model, the bottom edge of the volume element was fixed, the sides of the model were considered to be free and on the top, a displacement boundary condition was applied. In random model, in addition to the displacement and constrained boundary conditions applied to the top and bottom edges, respectively, a periodic boundary condition was applied at all nodes on the right- and lefthand sides of the volume element.

In both modeling approaches (image processing based modeling and random modeling), a mesh of linear-2D plane strain elements was used. In the FE model, which was generated based on image processing, each pixel was considered as a single element. Therefore, as the pixels were in quadrilateral shape, the generated mesh consists of quadrilateral elements. Moreover, for the random model, grains were distinguished from grain boundaries during the meshing process; due to the small thickness of grain boundaries and in order for the aspect ratio of the elements to attain acceptable values, a fine mesh was used for boundaries, while for the grains a coarse mesh was employed for the computational efficiency considerations.

The properties of the ferrite phase and the phase boundary were determined by isotropic hardening. Then, the GTN damage model was used with the parameters explained in the previous section. Furthermore, an explicit solver was used with a mass scale which was selected based on trial and error to get acceptable results in accordance with the experimental observations.

\section{Comparison Between Results Obtained from SEM Image Processing Technique and Experimental Data}

In this section, the results obtained from the simulations which use SEM image processing technique for the microstructure geometry generation are compared with the experimental data. Three different regions of the produced material were selected, and SEM images were taken from them (Fig. 3). Afterward, three FE models were generated based on these SEM images and the simulation results were compared to ensure that results are robust and independent of the position from which the image was taken. In all simulations, the GTN damage model was used for the ferrite phase and the boundaries. Figure 11 demonstrates the stressstrain curves obtained from numerical simulations.

The average of the three curves obtained from image processing-based simulations is compared with the measured data in Fig. 12. The average yield point and ultimate stress are 624 and $956 \mathrm{MPa}$, respectively. The graph shows that the simulation predictions are in a good agreement with the experimental results. The difference between the measured and predicted parameters, such as the yield point and ultimate stress, is less than $3 \%$ which shows the suitability of the presented image processing technique as well as the GTN damage model and its parameters. It is clear from Fig. 12 that the curves display trends similar to those measured, however, the only difference between the simulated and measured data is the drop off in the simulated curves after the strain corresponding to the ultimate stress. This difference stems from the use of the GTN damage model, in which the material does not fail instantaneously.
Fig. 11 Stress-strain diagram obtained from three different numerical simulations (the FE models created based on different SEM images)

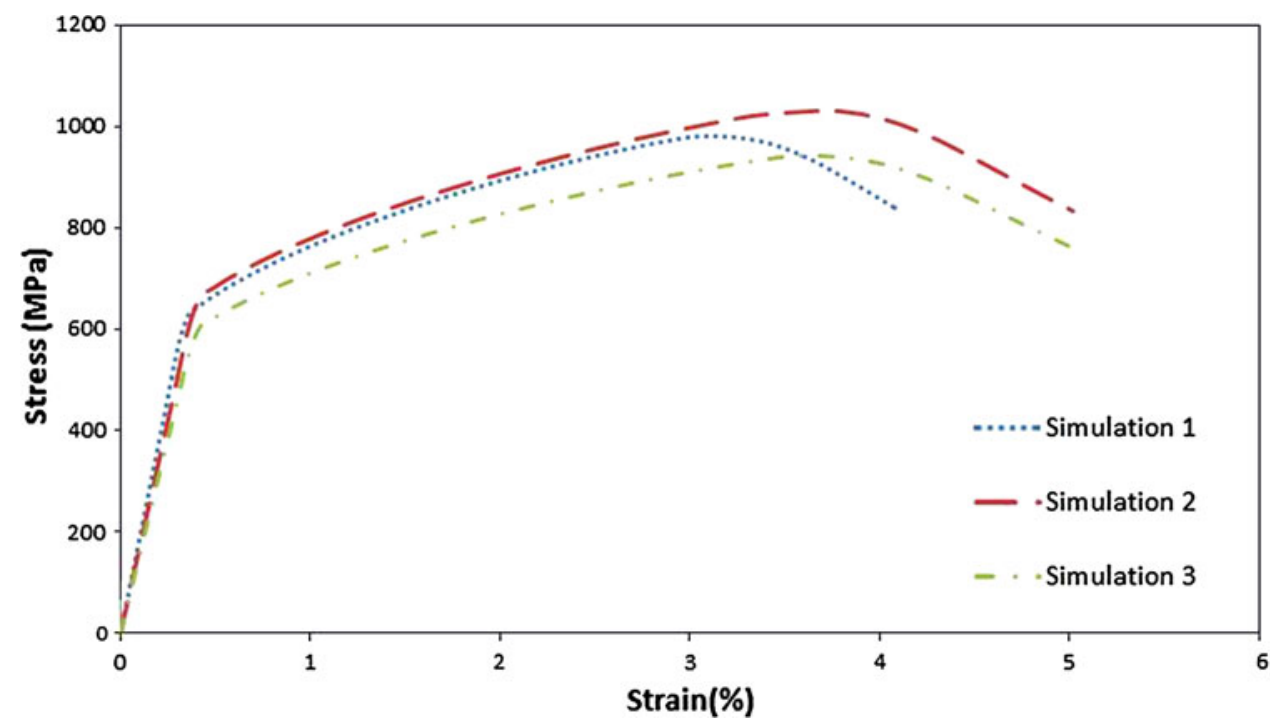


Fig. 12 Comparison between the stress-strain curves obtained from experiment and image processing-based simulations

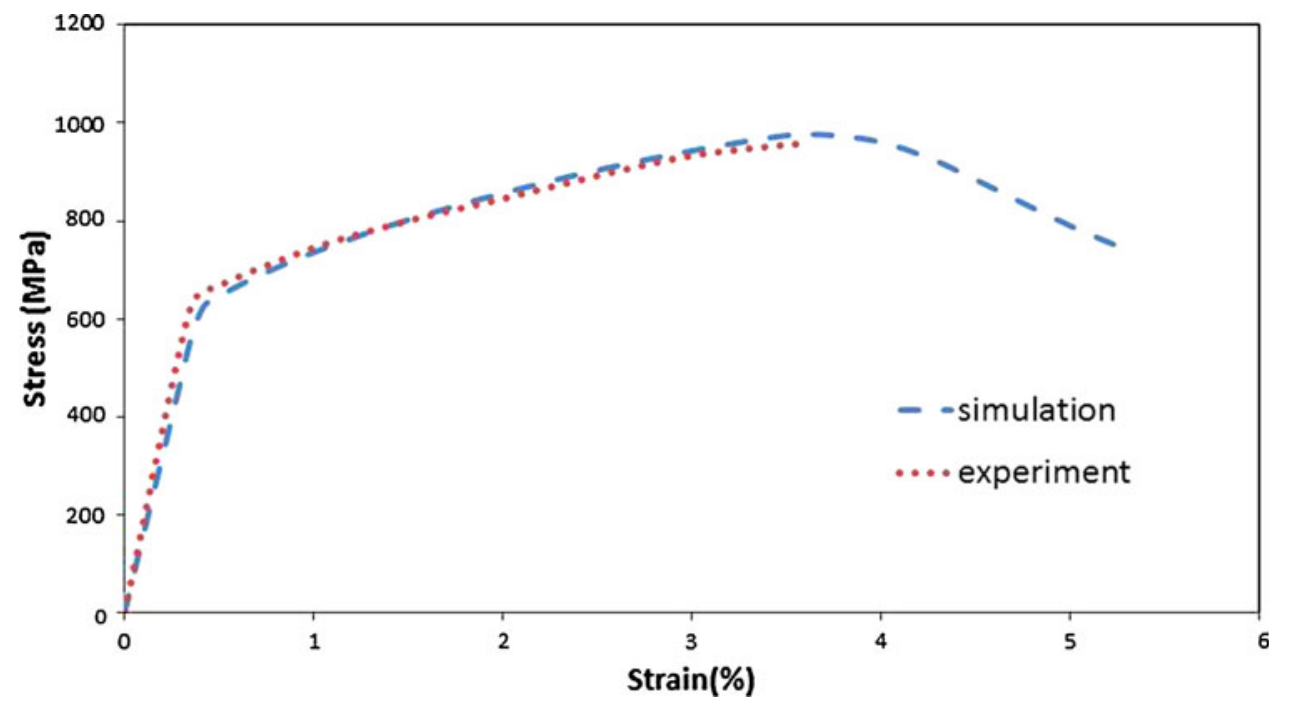

Strain
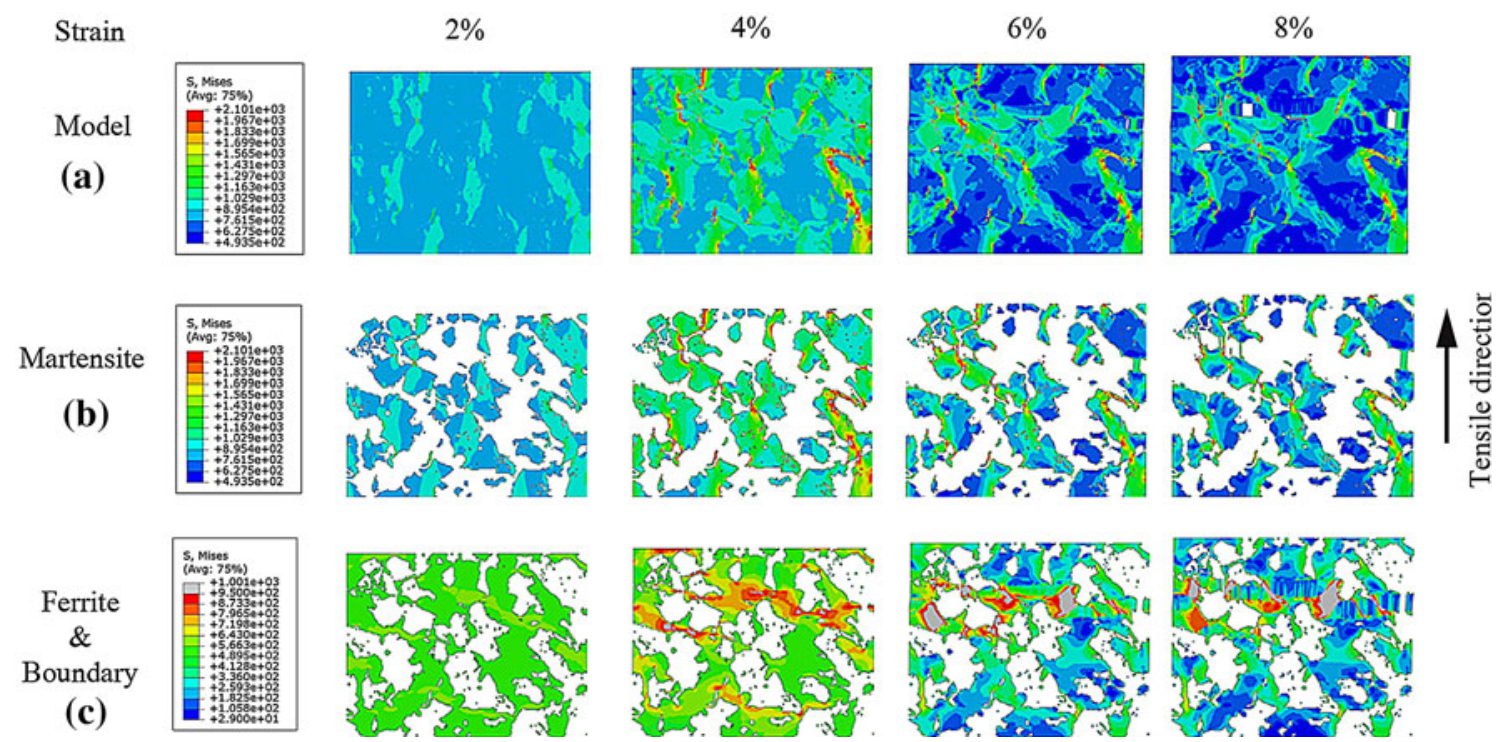

Fig. 13 Stress distributions in different phases of the material at different loading steps (region 1 in Fig. 3). (a) The whole model. (b) Martensite grains. (c) Ferrite grains and boundaries

Figure 13 shows the von Mises stress on the model by increasing the level of the applied strain. It should be mentioned that the region shown in this picture was in the middle of the volume element away from the influence of the boundaries. In the first step, as shown in Fig. 13(a, b), by increasing the strain, the stress level in martensite grains increases. When the applied strain is about $4 \%$, which is the martensite's critical failure strain, the stress concentration in some martensite grains reaches its ultimate value. At about $6 \%$ of applied strain, the stress in the martensite grains starts to diminish. This is mainly due to the overall reduction in stress after the ultimate stress in the stressstrain curve. In other words, the stress would reduce after a critical strain in the GTN model.
Looking at the ferrite grains, the stress is almost uniform up to a strain of $2 \%$. When the strain reaches a value of $4 \%$, the boundaries begin to fail and at the failure locations the ferrite grains undergo large stresses. Figure 13(c) illustrates a high stress concentration in a narrow area, which plays an important role in the deformation of ferrite grains. The failure line is actually the connection of lines in which the ferrite grains have high stress and are failing.

In summary, by increasing the strain, the deformation of ferrite grains increases. Further increase in strain causes the failure of the material and the nucleation of voids, mainly in boundary regions.

The triaxiality was calculated inside grains and at the phase boundaries. The results indicate that the average of 


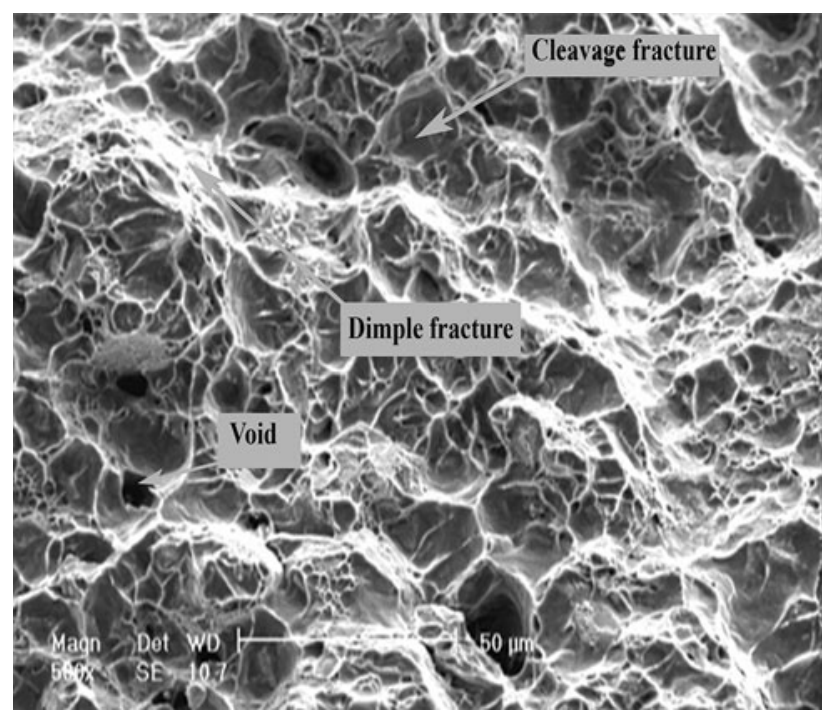

Fig. 14 SEM micrograph showing dimple and cleavage rupture mechanisms at the fracture zone

triaxiality at phase boundaries is more than two times higher than its value in the center of the grains. This verifies the fact that voids nucleate and grow in grain boundaries. Figure 13 clearly shows that the deformation of the material is accompanied by the nucleation of voids. The results show that the nucleation occurs in phase boundary areas.

In contrast to ferrite, martensite grains are rigid and can tolerate loading without large deformation. This results in a higher stress level in martensite grains in comparison to the ferrite grains.

The suggested mechanism is in accordance with the typical fracture mechanism of DP steels reported in the literatures $[2,15]$.

Figure 14 shows the SEM micrograph of tensile samples fractured at room temperature. As can be observed, the fracture surface contains both ductile and brittle features. In other words, both cleavage facets and dimples can be seen in Fig. 14. This mixed mode of dimple rupture and cleavage is often called quasi-brittle fracture. Cleavage and dimple fraction areas in Fig. 14 can be compared with the ferrite/ martensite volume fractions obtained from SEM images of the microstructure (Fig. 3). As is known, ferrite is a ductile phase and fractures with void formation and coalescence and, therefore, will usually be fractured with dimpled features. On the other hand, martensite is a brittle phase and usually fractures in cleavage mode. It is seen that transgranular cleavage facets due to martensitic fracture regions are surrounded by small and shallow dimples of ferrite rupture. There are also some deep dimples that generally exist in the interphase between the cleavage and surrounding dimpled areas. It could be said that primary voids are responsible for these deep dimples and, therefore, voids should be formed at first in the interface of martensite and ferrite.
As was discussed earlier, the fracture occurs in the regions where ferrite grains experience severe deformation, and as a result voids would nucleate in these areas. Dimples can be observed in the fracture surface of the tensile specimen shown in Fig. 14. They are indications for void initiation in the material. On the other hand, the martensite will fail by cleavage mechanisms in regions where stress concentration occurs.

Comparison Between Results Obtained from Random Geometry Generation and Experimental Data

In this section, the polycrystal topology is created by a random geometry technique based on the Voronoi tessellation [16]. Based on the data represented in Figs. 7 and 8, three different random microstructures with ferrite and martensite grain sizes of 15 and $14 \mu \mathrm{m}$ were constructed. As the number of grains in SEM images was in the range of $80-100$, therefore, a number of 100 grains was placed in all random images. The global properties of all models are equal but the distribution of ferrite and martensite grains in the models are different.

In this section, the properties of phases, boundaries, and GTN damage parameters are similar to those which were used for the image processing method of "Comparison between results obtained from SEM image processing technique and experimental data" section. As mentioned previously, the mesh size of the boundaries was considered smaller than the mesh size of the grains to develop a more precise simulation of the interaction between the boundaries and the grains. A typical mesh for a portion of the model is depicted in Fig. 15.

Figure 16 shows the calculated stress-strain diagrams from three models with random microstructures. These macroscopic stress-strain responses were obtained through a homogenization procedure as follows. Macroscopic stress for discrete FE volume is defined as

$\sum_{i j}=\frac{\sum_{1}^{n} \sigma_{i j} \forall_{n}}{\forall}$

where $n$ is number of finite elements and $\forall_{n}$ is volume of $n$th element. The strains are calculated analogous:

$E_{i j}=\frac{\sum_{1}^{n} \varepsilon_{i j} \forall_{n}}{\forall}$

The plot is for equivalent stress on the basis of equivalent strain. The equivalent stress is calculated by

$\sum_{\text {eqv }}=\sqrt{\frac{3}{2} \sum_{i j}^{\prime} \sum_{i j}^{\prime}}$

in which

$\sum_{i j}^{\prime}=\sum_{i j}-\left(\frac{1}{3}\right) \sum_{k k}$ 
Fig. 15 Mesh of grains and boundaries created by the random geometry technique
Fig. 16 Engineering stressstrain diagrams obtained from different random models
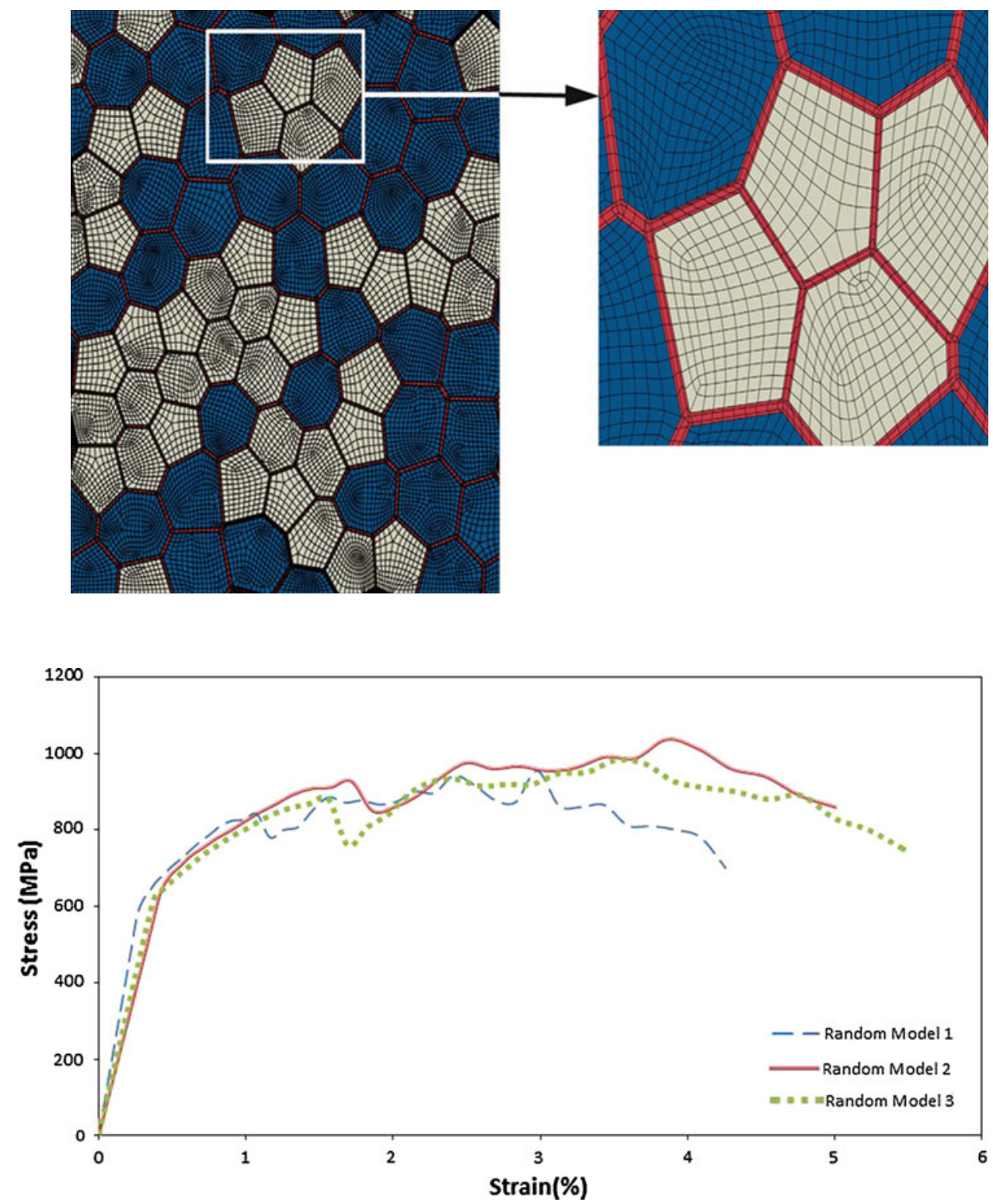

and equivalent strain can also be calculated by

$E_{\text {eqv }}=\sqrt{\frac{2}{3} E_{i j} E_{i j}}$

in which

$E_{i j}=E_{i j}-\left(\frac{1}{3}\right) E_{k k}$.

Figure 16 indicates that the results are independent of grain topology. In addition, it should be mentioned that the disturbances are due to the grain's sharp geometrical shapes. The maximum difference between the results is about $10 \%$ for the various random models.

The average of the above three stress-strain curves is compared with the experimental results in Fig. 17. The agreement between the results is acceptable, and the maximum difference is about $10 \%$. The yield stress estimated from the random model simulation and experimentation is approximately 620 and $640 \mathrm{MPa}$, respectively. The ultimate stress predicted from both diagrams is around $960 \mathrm{MPa}$ and the material failure strain is $3.5 \%$.

Figure 18(a) shows that when the steel fails in the Voronoi crystal model, a void is initiated from the boundary and then propagates through it. This is similar to the results obtained from the image processing simulation in which some voids initiate between phases and then expand over the length of the grain boundary path. However, some voids in the image processing simulation may grow in the boundary or through the ferrite grains.

As shown in Fig. 18(a), according to the simulation results, voids initiate from areas between two martensite grains. By increasing the strain level, the martensite grains are separated from each other which is in agreement with 
Fig. 17 Comparison between stress-strain diagrams obtained from the random model-based simulations and experiment

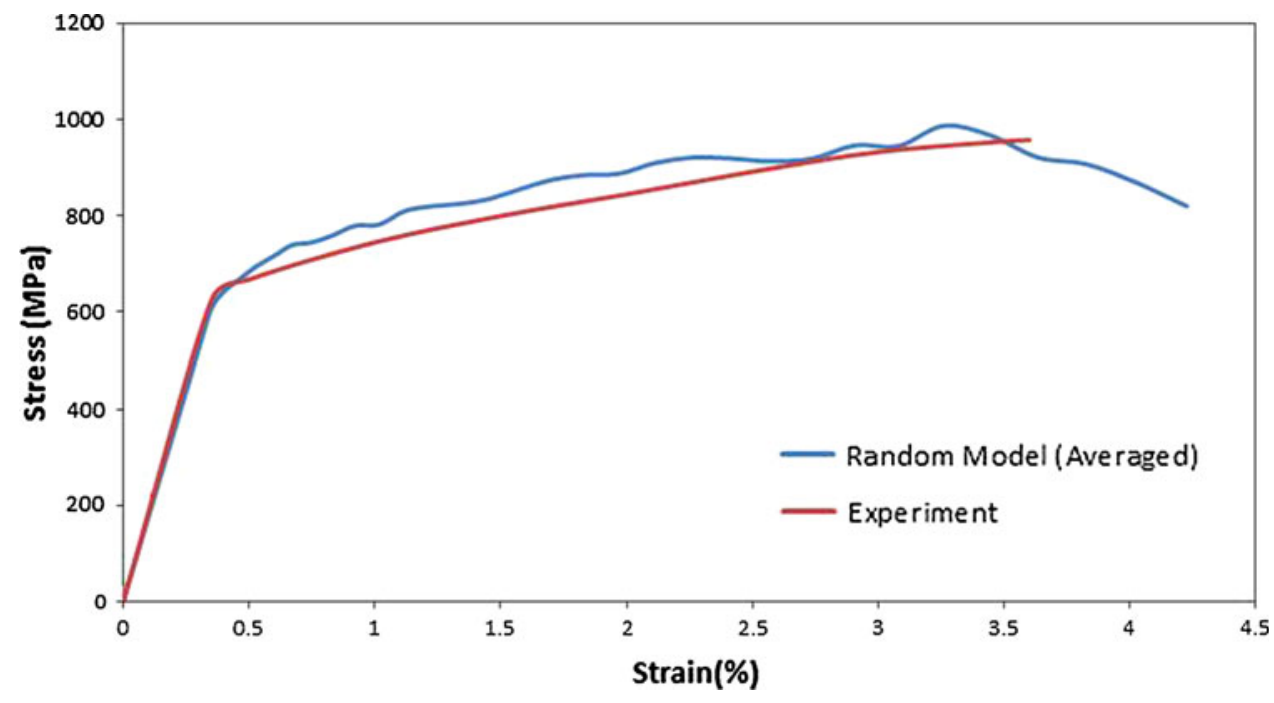

(b)

(c)

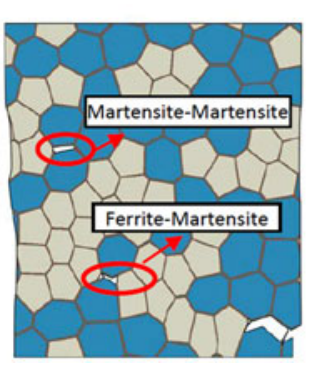

(d)

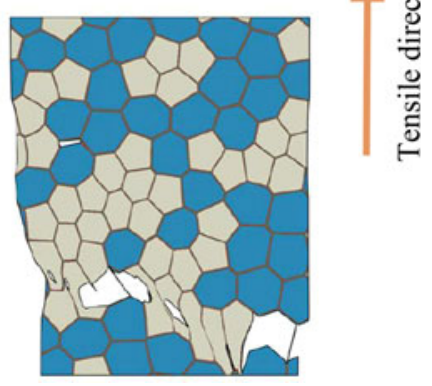

Fig. 18 Deformation of different phases of material at different load steps. (a) Strain 4\%. (b) Strain 6\%. (c) Strain 8\%. (d) Strain 10\% (randomly created model, red boundary, blue martensite grains, gray ferrite grains, white voids)

the experimental observations reported in the literature for high density martensite DP steels [2]. By further increasing the applied strain, the voids expand and cracks start growing between the ferrite and martensite grains (Fig. 18b). This phenomenon can also be observed in the SEM images taken from the DP steel [2]. In the next phase of deformation when the strain is $8 \%$, the damage propagates through the ferrite grains (Fig. 18c). This causes severe deformation of the material in the phase boundary region and ferrite grains. Separated boundaries and damaged ferrite grains eventually coalesce together and direct the final failure and breakage of the model (Fig. 18d).

The von Mises stress distribution over the grains shows a trend similar to that observed in the model created from image processing approach. The results indicate that at a strain of $4 \%$, the value of the stress on the martensite grains is higher than that on the ferrite ones. Again, at the points in which the void is initiated, the level of stress has reduced.

The results of simulations indicate that the modelling of phase boundaries play an important role in predicting the failure mechanisms of the material, and by incorporating the boundaries into the model it is possible to properly forecast the failure mechanisms of DP steels.

The results obtained from the finite element model show that the failure always initiates at boundaries and then grows over them to form the final failure of the material. However, the experimental observations show that in addition to the boundaries, failure can occur inside the ferrite grains. Therefore, a better model is required to more accurately simulate the different mechanisms involved in the failure of DP steels.

\section{Conclusions}

Experimental and numerical investigations were carried out to study the characteristics and failure mechanisms of DP steels. Two different models were constructed based on SEM images by employing two approaches: image processing technique and the Voronoi tessellation method. 
The results of the measurements showed that the failure pattern for ferrite and grain boundaries is not severely deviated from classical ductile failure. For this reason, the GTN damage model was assigned to the ferrite grains and to the phase boundaries. The stress-strain curves obtained from experimental and numerical results showed a good degree of correlation. The results also indicated that the relative deformation of martensite grains causes high deformation localization in the ferrite matrix and plays an important role in the final failure of the material. The failure of boundaries between ferrite-ferrite or ferritemartensite grains initiates void nucleation and growth. The slip of the martensite grains on each other causes severe deformation of the boundaries located between them, which results in the accelerated failure of the material.

\section{References}

1. V. Uthaisangsuk, U. Prahl, W. Bleck, Micromechanical modeling of damage behavior of multiphase steels. Comput. Mater. Sci. 43, 27-35 (2008)

2. J. Kadkhodapour, A. Butz, S. Ziaei-Rad, S. Schmauder, A micro mechanical study on failure initiation of dual phase steels under tension using single crystal plasticity model. Int. J. Plast. 31, 1103-1125 (2011)

3. A.P. Coldren, G. Tither, Development of a $\mathrm{Mn}-\mathrm{Si}-\mathrm{Cr}-\mathrm{Mo}$ asrolled dual phase steel. J. Met. 30, 6 (1978)

4. R.G. Davies, The deformation behavior of a vanadium-strengthened dual phase steel. J. Metall Trans. A 9, 41-52 (1978)

5. A. Kumar, S.B. Singh, K.K. Ray, Influence of bainite/martensitecontent on the tensile properties of low carbon dual-phase steels. J. Mater. Sci. Eng. A-Struct. 474, 270-282 (2008)

6. N. Saeidi, A. Ekrami, Comparison of mechanical properties of martensite/ferrite and bainite/ferrite dual phase 4340 steels. J. Mater. Sci. Eng. A-Struct. 523, 125-129 (2009)

7. N.J. Kim, G. Thomas, Effect of morphology on the mechanical behavior of a dual phase Fe/2Si/0.1C steel. J. Metall. Trans A 12, 483-489 (1981)

8. Y. Tomota, I. Tamura, Mechanical behavior of steels consisting of two ductile phases. Trans. Iron Steel. Inst. Jpn. 22, 665-677 (1982)

9. H.P. Shen, T.C. Lei, J.Z. Liu, Microscopic deformation behavior of martensitic-ferritic dual phase steels. J. Mater. Sci. Eng. 2, 28-33 (1986)
10. F. Roters, Application of crystal plasticity FEM from single crystal to bulk polycrystal. Comput. Mater. Sci. 32, 509-517 (2005)

11. S. Kang, H. Kwon, Fracture behavior of intercritically treated complex structure in medium-carbon $6 \mathrm{Ni}$ steel. J. Metall. Trans. A 18, 1587-1592 (1987)

12. M. Ohata, M. Suzuki, A. Ui, F. Minami, Simulation of ductile failure in two-phase structural steel with heterogeneous microstructure. J. Eng. Fract. Mech. 77, 277-284 (2010)

13. Y.J. Wei, L. Anand, Grain-boundary sliding and separation in polycrystalline metals: application to nanocrystallinefcc metals. J. Mech. Phys. Solids 52, 2587-2616 (2004)

14. Y.J. Wei, C. Su, L. Anand, A computational study of mechanical behavior of nanocrystalline fcc metals. J. Acta Mater. 54, 3177-3190 (2006)

15. Y.J. Wei, L. Anand, On micro-cracking, inelastic dilatancy, and the brittle-ductile transition in compact rocks: a micro-mechanical study. Int. J. Solids Struct. 45, 2785-2798 (2008)

16. V. Ziaei-Rad, N. Nouri, S. Ziaei-Rad, M. Abtahi, A numerical study on mechanical performance of asphalt mixture using a meso-scale finite element model. Finite Elem. Anal. Des. 57, 81-91 (2012)

17. X. Sun, K.S. Choi, W.N. Liu, M.A. Khaleel, Predicting failure modes and ductility of dual phase steels using plastic strain localization. Int. J. Plast. 25, 1888-1909 (2009)

18. X. Sun, K.S. Choi, A. Soulami, W.N. Liu, M.A. Khaleel, On key factors influencing ductile fractures of dual phase (DP) steels. J. Mater. Sci. Eng. A 526, 140-149 (2009)

19. R. Rodriguez, I. Gutierrez, in Proceedings of the TMP'2004, ed. by M. Lamberigts (Verlag Stahleisen GMBH, Düsseldorf, 2004), p. 356

20. J. Kadkhodapour, S. Schmauder, D. Raabe, S. Ziaei-Rad, U. Weber, M. Calcagnotto, Experimental and numerical study on geometrically necessary dislocations and non-homogeneous mechanical properties of the ferrite phase in dual phase steels. J. Acta Mater. 59, 4387-4394 (2011)

21. X. Gao, J. Kim, Modeling of ductile fracture: significance of void coalescence. Int. J. Solids Struct. 43, 6277-6293 (2006)

22. J. Faleskog, X. Gao, C.F. Shih, Cell model for nonlinear fracture analysis-I. Micromechanics calibration. Int. J. Fract. 89, 355-373 (1998)

23. A.G. Franklin, Comparison between a quantitative microscope and chemical methods for assessment of non-metallic inclusions. J. Iron Steel Inst. 207, 181-186 (1969)

24. J. Kim, X. Gao, T.S. Srivastan, Modeling of void growth in ductile solids: effects of stress triaxiality and initial porosity. J. Eng. Fract. Mech. 71, 379-400 (2004) 